University of Nebraska - Lincoln

DigitalCommons@University of Nebraska - Lincoln

Publications of the Research Compliance

Services Staff

Research Compliance Services

September 2007

\title{
Prevention over Cure: The Administrative Rationale for Education in the Responsible Conduct of Research
}

Daniel R. Vasgird

University of Nebraska - Lincoln, dvasgird2@unl.edu

Follow this and additional works at: https://digitalcommons.unl.edu/researchcompsvcspubs

Part of the Higher Education Administration Commons

Vasgird, Daniel R., "Prevention over Cure: The Administrative Rationale for Education in the Responsible Conduct of Research" (2007). Publications of the Research Compliance Services Staff. 2.

https://digitalcommons.unl.edu/researchcompsvcspubs/2

This Article is brought to you for free and open access by the Research Compliance Services at DigitalCommons@University of Nebraska - Lincoln. It has been accepted for inclusion in Publications of the Research Compliance Services Staff by an authorized administrator of DigitalCommons@University of Nebraska - Lincoln. 


\title{
Prevention over Cure: The Administrative Rationale for Education in the Responsible Conduct of Research
}

\author{
Daniel R. Vasgird, PhD, CIP
}

\begin{abstract}
The value of responsible conduct of research (RCR) education from an administrative perspective can be summed up in the oft-used adage, an ounce of prevention is worth a pound of cure. The National Academy of Sciences has underscored the importance of RCR education in three major reports relating public trust in research to the perception and reality of integrity within the field. Compliance and integrity cannot simply be hoped
\end{abstract}

for. Rising numbers of reported cases of research misconduct support this view. This scenario calls for institutions to provide an environment where research integrity is a fundamental prerequisite. Supporting this notion is the adoption by federal oversight agencies of the compliance elements delineated in the Federal Sentencing Guidelines for Organizations as a guide for determining whether an institution promotes a culture of integrity. RCR education is most valuable to the administrator in raising the awareness of researchers regarding compliance and integrity issues and thereby reducing the risk of infraction. In turn, the overall level of confidence among users and supporters may be improved also. Therefore, RCR education has become a primary operational arm of administration in the quest for institutional stability. cience offers humanity its greatest tool for the enhancement of health, well-being, knowledge, and security in a very unpredictable world. These are high aspirations and difficult to attain under the best of circumstances. Research organizations are no different than their counterparts in other fields, in that effective and efficient management practices aimed at smooth internal operations are, by necessity, going to be the focus of administrators' attention. Measures that add to effectiveness and diminish obstruction such as responsible conduct of research education should be a focal part of top management's vision.

\section{Prevention versus Cure}

Considering that a research institution's goal is the generation and dissemination of new knowledge, the value of responsible conduct of research (RCR) education from an administrative perspective can be summed up in the oft-used adage, an ounce of prevention is worth a pound of cure. For example, often investigators involved in a timeand resource-consuming conflict of interest or research misconduct matter say they were never informed about regulatory requirements and ethical expectations within an institution. Similarly, graduate students and postdocs often complain of having received no research integrity training whatsoever. A broad and comprehensive RCR education program can be invaluable in diminishing any communication and knowledge gap that might exist between institutional policy makers and those whom the policies may affect. Most important, RCR education can be used to lay the solid conceptual foundation for ethical research. It is most effectively aimed at delineating the parameters of expected attitudes and behavior and illustrating them for future reference. To borrow from Frank Macrina, ${ }^{1}$ RCR education is best understood as the use of didactic measures to invoke "an overarching philosophy of behavior," conceptually encompassing the four areas of human and animal research protections, research integrity, environmental and safety issues, and fiscal accountability.

More broadly, North American scientific associations and research institutions have become increasingly proactive in advocating research compliance and its integrity sibling, the responsible conduct of research, in light of the rising stature of and dependence on science in our society. Heightened scrutiny from the media, advocacy groups, and government has followed this rising prominence and the concomitant increased funding of research. The
National Academy of Sciences (NAS) has issued three major reports since 1989 advocating more emphasis on research integrity in academic science, clearly stating that the higher profile and greater financial support of science has increased competition and pressure for investigators to achieve, with their attendant ills as well as benefits. ${ }^{2-4}$ The practical side of this concern is summarized in the introduction to the most recent NAS publication on this subject, Integrity in Scientific Research: "The public will support science only if it can trust the scientists and institutions that conduct research."4 (p. 1)

With this generally understood assertion in mind, the question becomes whether the research community is up to the challenge of maintaining that trust. Derek Bok, ${ }^{5}$ former president of Harvard University, recently averred that "most universities have not done all they should to protect the integrity of their research. Many have not even shown that they are seriously concerned about doing so." It does not bode well that the 2005 annual report of the U.S. Department of Health and Human Services Office of Research Integrity (ORI) documents that a record number of institutions reported the highestever number of new cases of research misconduct. $^{6}$ 


\section{Compliance and Integrity}

In academic science, the role of institutional administration is to develop policies, practices, and means that will support and guide the research enterprise in its pursuit of new knowledge. The value of RCR to the administrator is in raising the awareness of researchers regarding compliance and integrity issues and thereby reducing the risk of infraction or misconduct.

Compliance has had a featured role in the research arena since the earliest days of federal funding, but recently integrity has interwoven itself with compliance as an explicit rather than a presumed principle. What has become obvious from an administrative perspective is that researchers want regulatory and ethical guidance, and that compliance and integrity cannot simply be hoped for without sometimes fateful results for individual investigators and institutions alike. Although providing RCR education is certainly part of academic researchers' responsibility for mentoring their trainees and fostering their professional growth, RCR education has also become a primary operational arm of administration in the quest for institutional stability. Institutional administrations must, however, ensure readily available expertise in RCR education and a grasp of the complexity of the issues, if they are to garner their researcher colleagues' respect.

The Council on Governmental Relations (COGR), an association of research universities, offers a vivid example of this progression in the latest revision of its widely cited document, Managing Externally Funded Research Programs: A Guide to Effective Management

Practices. ${ }^{7}$ Twelve basic principles lie at the heart of COGR's recommendations for quality management of the academic research enterprise, with the need for effective compliance interwoven throughout. In the most recent versions of the document, research integrity is listed as a basic principle of quality management, emphasizing that it is no longer enough for administrators to presume that it is being attended to informally. Underscoring the progress in this area, one of COGR's research integrity indicators for demonstrating institutional commitment reads as follows: "The institution provides an environment where responsible conduct of research is a fundamental prerequisite in the design, conduct and reporting of research data and results." 7 (p. 50)

Another example of the growing focus on RCR education as a preventive mechanism is offered in the recent revision of the ORI's Public Health Service Final Misconduct Rule. Under Subpart C, Responsibilities of Institutions [ $\$ 93.300(\mathrm{c})]$, the new rule states in no uncertain terms that "institutions under this part must foster a research environment that promotes the responsible conduct of research." 8 (pp. 283-88) RCR education and training are the most viable, efficient, and farreaching components in this process. Without them it is virtually impossible to nurture an environment that values and supports ethical behavior. The ORI goes one step further and, in its guidance section for this new rule, borrows from the previously mentioned NAS publication, Integrity in Scientific Research, when it maintains in sine qua non fashion that "instruction in the responsible conduct of research need not be driven by federal mandates, for it derives from a premise fundamental to doing good science: the responsible conduct of research is not distinct from research.," (p9) In other words, the ability to conceive of and actually do science both at institutional and individual levels depends on responsibility as the fundamental element, with education as the best means for conveying that message and fostering responsibility.

\section{The Elements of Compliance}

A short time ago, I had a discussion with a senior staff member in the Inspector General's Office of the National Science Foundation who noted that the fulfillment of institutional responsibility from an inspector's standpoint plays out when an investigation ensues under the compliance rubric. She noted that there is concurrence with this approach in the Department of Health and Human Services Inspector General's Office also. In addition to the usual procedural steps, inspectors look closely to determine whether the institution has promoted an organizational culture that encourages integrity and compliance. They use the following recommended compliance elements listed in chapter eight of the Federal Sentencing Guidelines for Organizations (FSGO) ${ }^{9}$ as a guide for making this determination:

- implementing written policies and procedures;

- designating a compliance officer and compliance committee;

- conducting effective training and education;

- developing effective lines of communication;

- conducting internal monitoring and auditing;

- responding promptly to detected problems and undertaking corrective action; and enforcing standards through well-publicized disciplinary guidelines.

Institutions that have a proactive compliance and ethics plan in place receive credit on their overall “culpability score." Kenneth Johnson, in an Ethics Resource Center article, points out that fulfillment of the seven requirements is "the hallmark of an effective program that encourages compliance with the law and ethical conduct." ${ }^{10}$ He points out, however, that the FSGO creators continuously signal "that these "seven minimum requirements' are not so much the 'elements' of an effective program as they are 'indicators' that due diligence and promotion of the desired culture occurred."10

From an administrative standpoint, support is the key word in this context, raising the question, what do we have to do institutionally to maintain support from within and without for research to prosper and succeed? With practicality as the focus, those who administer research institutions are called on to create an ideal research environment. My Inspector General colleague emphasized that federal inspectors look very closely at how well an institution fulfills the training, education, and communication elements of compliance, as well as the emphasis that it places on the responsible conduct of research in general. The ideal research environment, 
then, is one that provides effective training and education, develops effective lines of communication, and generally promotes the responsible conduct of research. In the end, from an administration perspective, RCR education in the service of compliance, responsibility, and practicality works to tie these processes together into an effective symbiotic troika.

\section{Conclusion}

For individuals, living an ethical life within societal bounds depends on the ability to conceive of an ethical ideal, aspire to it, and abide by its dictates to the best of one's ability. In turn, the leaders of a truly ethical research institution try to the best of their ability to foster and crystallize the conception of the ideal in the hearts and minds of its constituents. As Richard Livingstone put it, "One is apt to think of moral failure as weakness of character; more often it is due to an inadequate ideal." 11 The ideal should be thought of as something tangible in terms of personal imagery, composed of a blend of policies, regulations, and institutional values. It is the role of research institutions that wish to flourish to provide the means for their community members to internalize these ideals. This can only be done with a consistent message and support from the highest echelon of the administration on down. The operative principle is that the vast majority of those engaged in the research enterprise want to do the right thing. Often lacking, however, is the information and guidance researchers need for a clear understanding of the institution's internal culture. Therein lies the true value of comprehensive RCR education. It behooves a prescient administration to take this to heart.

\section{Acknowledgments}

The author would like to thank John Masten for his insights and support of RCR education at a time when few were so inclined.

\section{References}

1 Macrina, F. Scientific Integrity: Text and Cases in Responsible Conduct of Research. 3rd ed. Washington, DC: ASM Press; 2005.

2 Institute of Medicine, Committee on the Responsible Conduct of Research, National Research Council. The Responsible Conduct of Research in the Health Sciences. Available at: http:// www.nap.edu/books $/ 0309062373 / \mathrm{html}$. Accessed May 9, 2007.

3 National Academy of Sciences, Panel on Scientific Responsibility and the Conduct of Research, National Academy of Sciences, National Academy of Engineering, Institute of Medicine. Responsible Science, Volume I: Ensuring the Integrity of the Research Process. Washington, D.C.: The National Academies Press; 1992. Available at: (http://www.nap.edu/books/0309047315/ html . Accessed May 9, 2007.

4 Institute of Medicine, Board on Health Sciences Policy and Division of Earth and Life Studies, Institute of Medicine and National Research Council of the National Academies. Integrity in Scientific Research: Creating an Environment That Promotes Responsible Conduct. Available at: http://www.nap. edu/books $/ 0309084792 / \mathrm{html}$. Accessed May 9, 2007.

5 Bok, D. Universities in the
Marketplace: The Commercialization of Higher Education. Princeton, NJ: Princeton University Press; 2003.

6 Department of Health and Human Services, Office of Research Integrity. Office of Research Integrity Annual Report 2005. Available at: http://ori. dhhs.gov/documents/annual_reports/ori annual report 2005.pdf. Accessed May 9, 2007.

7 Council on Government Relations. Managing Externally Funded Research Programs: A Guide to Effective Management Practices. Available at: http://www.cogr.edu/files/publications goodmanagement.cfm . Accessed May 9, 2007.

8 U.S. Department of Health and Human Services. Public Health Service Policies on Research Misconduct; Final Rule. Available at: ( http://ori.dhhs.gov/ documents $/ 42$ cfr_parts 50 and 93 2005.pdf). Accessed May 9, 2007.

9 United States Sentencing Commission. 2004 Federal Sentencing Guidelines. Available at: http://www.ussc.gov/ 2004guid/8b2_1.htm. Accessed May 9, 2007.

10 Johnson, K. W. Federal sentencing guidelines: seven minimum requirements. Available at: http://www.ethics.org/ercpublications/staffarticles.asp?aid $=773$. Accessed June 19, 2007.

11 Evans, L. H. The magnificent purpose. Phylon. 1949; 10:314.

Daniel Vasgird is Director of Research Compliance Services at the University of Nebraska-Lincoln. Correspondence should be addressed to Office of Research Compliance Services, University of Nebraska-Lincoln, 312 N. 14th St., Suite 209, P.O. Box 880408, Lincoln, NE 685880408; tel 402 472-1837; fax 402 472-6048; email dvasgird2@unl.edu . 